Original Article

\title{
The effects of respiratory muscle strengthening exercise using a sling on the amount of respiration
}

\author{
Seung-Ju Yi, PT, PhD ${ }^{1)}$, Jin-SeOP Kim, PT, PhD²* \\ 1) Department of Physical Therapy, Andong Science College, Republic of Korea \\ 2) Department of Physical Therapy, Sunmoon University: 70 Sunmoon-ro, 221 beon-gil, \\ Tangjeong-myeon, Asan-si, Chungnam 336-708, Republic of Korea
}

\begin{abstract}
Purpose] The purpose of this study was to present aerobic exercise that can be performed together with respiratory muscle strength training and examine whether the vital capacity of individuals can be enhanced when respiratory muscle strength training is conducted together with aerobic exercise. [Subjects and Methods] The subjects were 10 male students and 8 female students. The sling exercise method was used to conduct three types of training to strengthen the muscles around the shoulder joints. A maximal respiratory quotient measurement device was used to measure the vital capacity of the subjects five times. [Results] There was a significant difference in each respiratory training time point compared with before the performance of respiratory training. [Conclusion] This study presented respiratory muscle strength training using a sling as a training method for respiratory training. Key words: Sling, Aerobic exercise, Respiratory
\end{abstract}

(This article was submitted Feb. 25, 2015, and was accepted Mar. 24, 2015)

\section{INTRODUCTION}

Ventilation between air and blood occurs through neurological control of the respiratory muscles ${ }^{1)}$. Muscles related to respiration may be divided into inspiratory and expiratory muscles. Major muscles engaging in inspiration include the diaphragm and external intercostal muscle, and minor muscles engaging in inspiration encompass the sternocleidomastoid muscle, scalene muscle, trapezius muscle, pectoralis major muscle, pectoralis minor muscle, and serratus anterior muscle. These muscles act during forced expiration. Expiratory muscles that do not act in normal respiration but do act in strong respiration include the rectus abdominis muscle, musculus transversus abdominis, external/internal oblique abdominal muscle, and internal intercostal muscle. Weakening of the respiratory system muscles is a risk factor for cardiovascular disease, and these muscles play a role in reducing the pressure of the lower abdomen during respiration $^{2,3)}$. Therefore, it has been reported that respiratory muscle strength training not only improves motor ability but also decreases dyspnea and nocturnal desaturation ${ }^{4)}$. For such a reason, in the clinical field, medical devices are used as interventions to improve the respiratory muscles of patients with chronic obstructive pulmonary disease, asthma, spinal cord injury, and muscle disease. To improve

*Corresponding author. Jin-Seop Kim (E-mail:

skylove3373@sunmoon.ac.kr)

(C2015 The Society of Physical Therapy Science. Published by IPEC Inc. This is an open-access article distributed under the terms of the Creative Commons Attribution Non-Commercial No Derivatives (by-ncnd) License $<$ http://creativecommons.org/licenses/by-nc-nd/3.0/> . respiration and prevent respiratory diseases, devices such as high-frequency chest wall oscillations devices, flutters, positive-pressure masks, and resistance breathing devices are used. Respiratory muscle training conducted with assistive devices for respiration has brought about improvements in respiratory muscles ${ }^{5,6)}$. According to recent research, inspiratory muscle training using inspiratory resistance devices strengthens inspiratory muscles ${ }^{7)}$, and respiratory training and the strengthening of inspiratory muscles has been shown to improve the quality of life of stroke patients ${ }^{8}$. Researchers have also reported that assistive devices like balloons may improve the vital capacity of smokers ${ }^{9)}$. However, previous researchers mostly conducted respiratory muscle training using assistive devices, and physical training to strengthen respiratory muscles has been lacking. In actuality, when aerobic exercise was conducted together with breathing exercise, respiratory muscles and pulmonary functions were enhanced ${ }^{10,11)}$. Therefore, the purpose of this study was to present aerobic exercise that can be performed together with respiratory muscle strength training and examine whether the vital capacity of individuals can be enhanced when respiratory muscle strength training is conducted together with aerobic exercise.

\section{SUBJECTS AND METHODS}

This study was conducted from May 27 to July 26, 2013, and involved 18 undergraduates living in Andong City, Republic of Korea. The subjects who participated in this study voluntarily participated, and consent to take part in this study was obtained from them. Among the subjects, there were 10 male students and 8 female students. Their average age, height, and weight were 21.5 years old, $168.5 \mathrm{~cm}$, and 
$63 \mathrm{~kg}$, respectively. The rate of smokers was $44.44 \%$, and the average duration of smoking was 3.5 years. A maximal respiratory quotient measurement device (Personal Best full range flow meter, Philips Respironice, Parsippany, NJ, USA) was used to measure the vital capacity of the subjects five times - prior to the exercise, two weeks after the exercise, four weeks after the exercise, six weeks after the exercise, and eight weeks after the exercise. The subjects sat in a chair, spread their shoulders, and grabbed the measurement device. Three measured values under the maximal expiratory condition were averaged. The sling exercise method was used to conduct three types of training to strengthen the muscles around the shoulder joints. The subjects conducted shoulder internal rotation, shoulder external rotation, and push-ups. Figure 1 shows a subject engaging in shoulder internal rotation. As a starting posture, the subjects spread their legs shoulder-width apart and looked straight forward in a neutral position. They then put on a wide sling band around their abdomen with their shoulders spread at 90 degrees and their elbows spread at 90 degrees, conducted external rotation of the shoulders while tilting their bodies forward, and conducted inspiration. Then again in the starting posture, the subjects conducted internal rotation of the shoulders and expiration. Figure 2 shows external rotation of the shoulder joints. As a starting posture, the subjects stood on a reference line facing backward with their legs shoulderwidth apart and looked straight forward in a neutral position. They then put a wide band around their abdomen and put down the red line to the location of acromion, maintained shoulder abduction at 90 degrees and elbow flexion at 90 degrees, and tilted their body backward. While internally rotating their shoulders, they pulled their body forward and breathed in, and at a starting posture again, they externally rotated their shoulders and breathed out. Figure 3 displays a subject doing a push-up. As a starting posture, the subjects spread their legs shoulder-width apart on a reference line and looked straight forward in a neutral position. They then put a broad band around their chest, and pulled down the red line to their finger joints, maintained shoulder flexion at 90 degrees and full elbow extension, spread their shoulders, and tilted their body forward and breathed in. At the starting posture again, they adducted their shoulders and breathed out. Three sets of the main exercise, with 10 repetitions per set, were conducted three times a week for eight weeks. The subjects rested for one minute between each set. Time required to perform all the exercises was 30 minutes. SPSS 18.0 version was used for statistical analysis in this study. In order to verify the normality of this study results, the Shapiro-Wilk test was conducted; the results were found to be normally distributed. Descriptive statistics were used to measure the general characteristics of the subjects. Repeated-measured analysis of variance was used to measure the effects of the muscle strengthening exercise; changes in vital capacity at each time point of measurement were measured. A paired comparison was conducted to look at differences in measurement time points. The significance level was set at 0.05 .

\section{RESULTS}

The results of this study revealed that there were signifi-
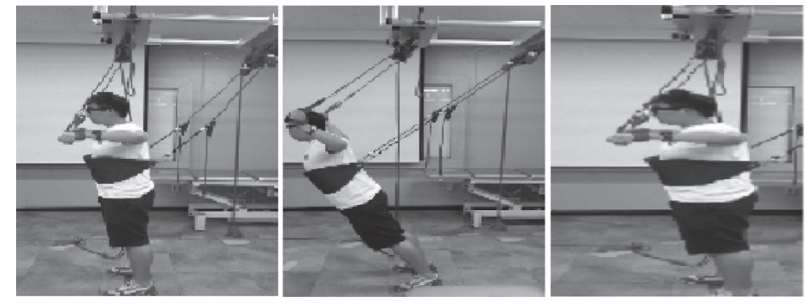

Fig. 1. Shoulder internal exercise
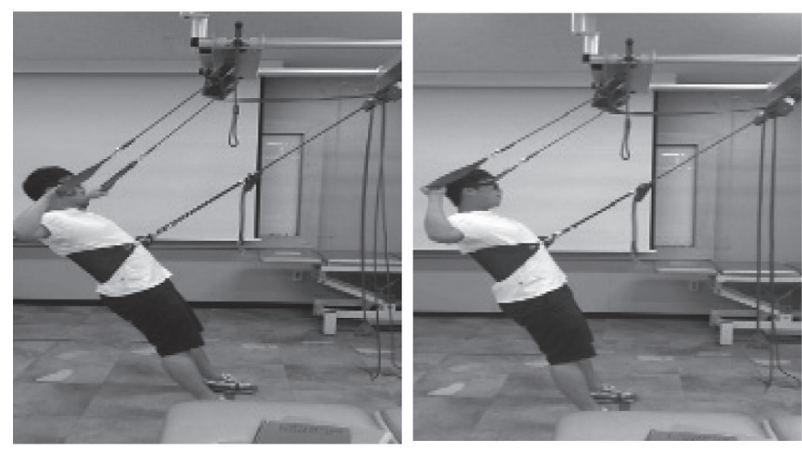

Fig. 2. Shoulder external exercise
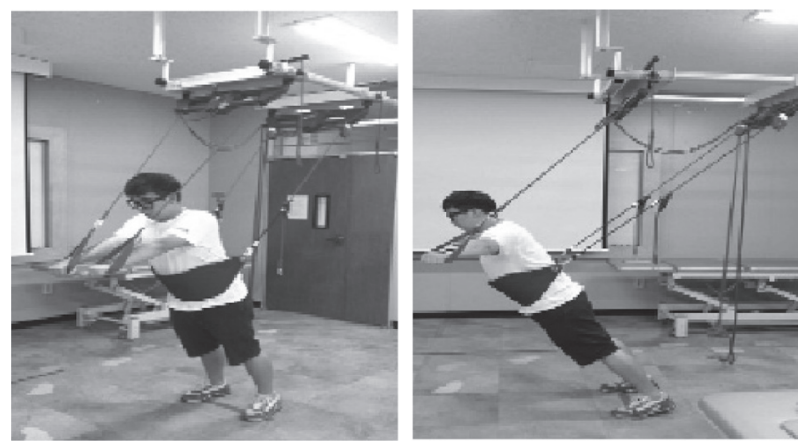

Fig. 3. Shoulder push-up exercise

cant differences among each of the respiratory training time points compared with before the performance of respiratory training $(\mathrm{p}<0.05)$. The paired comparison results showed that the eight weeks of respiratory training led to significant improvements compared with before the training and two weeks after the training $(\mathrm{p}<0.05)$. When respiratory training was conducted for six weeks, there were significant improvements compared with before the training $(p<0.05)$. The results of the respiratory training according to whether the subjects smoked or not revealed that there was no significant interaction $(\mathrm{p}>0.05)$ (Table 1).

\section{DISCUSSION}

This study was conducted to examine the effects of respiratory muscle strengthening and aerobic exercises for eight weeks using a sling on the vital capacity of individuals and 
Table 1. The result of the respiratory muscle strengthening exercise $(n=18)$

\begin{tabular}{lccccccc}
\hline & $\begin{array}{l}0 \text { weeks } \\
(\mathrm{M} \pm \mathrm{SD})\end{array}$ & $\begin{array}{c}2 \text { weeks } \\
(\mathrm{M} \pm \mathrm{SD})\end{array}$ & $\begin{array}{c}4 \text { weeks } \\
(\mathrm{M} \pm \mathrm{SD})\end{array}$ & $\begin{array}{c}6 \text { weeks } \\
(\mathrm{M} \pm \mathrm{SD})\end{array}$ & $\begin{array}{c}8 \text { weeks } \\
(\mathrm{M} \pm \mathrm{SD})\end{array}$ & $\mathrm{f}$ & Duration $\times$ smoker \\
\hline Nonsmoker & 419.0 & 444.0 & 464.0 & 468.0 & 510.0 & & \\
$(\mathrm{ml})$ & $(71.4)$ & $(78.6)$ & $(71.0)$ & $(66.0)$ & $(63.6)$ & \multirow{2}{*}{$0.4^{*}$} & 0.4 \\
Smoker & 375.0 & 398.8 & 400.0 & 411.3 & 412.5 & & \\
$(\mathrm{ml})$ & $(51.6)$ & $(35.6)$ & $(56.1)$ & $(74.3)$ & $(61.8)$ & & \\
\hline
\end{tabular}

${ }^{*} \mathrm{p}<0.05, \mathrm{M} \pm \mathrm{SD}:$ mean \pm standard deviation

to present an effective exercise method. According to the results, aerobic exercise combined with respiratory muscle strengthening exercise for at least six weeks improved the vital capacity of the subjects. Walker et al. ${ }^{12)}$ who obtained results similar to those of the present study, used an upper limb ergometer to measure the effect of exercise to improve muscle strength and enhance respiratory functions of spinal cord injury patients. HajGhanbari et al. ${ }^{13)}$ reported that diverse muscle strengthening and endurance training for respiratory muslces improved the motor and respiration abilities of sports athletes. Therefore, it is considered that the vital capacity of the subjects in the present study also improved because of enhancement of the strength and endurance of respiratory peripheral muscles using a sling. In the present study, respiratory training was conducted together with muscle strength training, and the motions of breathing in and out strengthened inspiratory muscles as well as expiratory muscles. Likewise, Kim and $\mathrm{Lee}^{9)}$ reported that when expiratory muscles were strengthened with a balloon, the respiratory function of the subjects was improved. Sutbeyaz et al. ${ }^{8)}$ reported that when inspiratory muscle training was conducted for six weeks, the respiratory function of stroke patients improved. This is due to the fact that respiratory function efficiency can be explained by the organic relationship between inspiration and expiration, and strengthening of the expiratory muscles has a close mutual relationship with inspiratory ability ${ }^{14}$. In the present study, there was a significant difference between the time before the training and after six weeks of training. The changes in respiratory capabilities by the sixth week likely occurred because training two to three times per week for at least six weeks may change muscle strength ${ }^{15)}$. Increased muscle strength improves the maximal oxygen intake amount as well as muscle endurance. In a similar study, Fiser et al. ${ }^{16)}$ achieved results similar to those of the present study: rapid response training such as walking increased the maximal oxygen intake amount and muscle strength of elderly people. Bossers et al. ${ }^{17)}$ reported that when muscle strengthening exercise was conducted together with aerobic exercise, there was a physical advantage, which was similar to the findings of the present study showing that combined with strengthening of respiratory peripheral muscles improved vital capacity. In the present study, the subjects showed changes in their amount of respiration by the sixth week of the intervention. However, Kim et al. ${ }^{7}$ reported that training using an assistive device for four weeks improved pulmonary functions. Sutbeyaz et al. ${ }^{8)}$ noted that respiratory function improved when respiratory training was conducted for at least six weeks. Kim and $\mathrm{Lee}^{9)}$ reported that blowing balloons for eight weeks resulted in improved respiratory ability. There are various views on exercise period, and therefore further research is considered necessary. The reason for the diverse results is because of differences in subjects and interventions. With regard to changes in the amount of respiration of the subjects according to whether they smoked or not, there was no interaction in the present study. Unlike the present study, Nowak et al. ${ }^{18)}$ reported that subjects who smoked for a long time would have an obvious negative effect due to excessive stress on their lungs. On the contrary, the subjects who participated in the present study were young healthy adults, and therefore, there was probably no interaction between exercise and whether they smoked or not. Similar to the findings of the present study, Taito et al. ${ }^{19)}$ reported that after smokers and nonsmokers received training of moderate intensity, there was no interaction between their oxygen consumption amount and whether they were smokers or not. The present study has several limitations. First, the participants were ordinary people. Second, there was no direct comparison of respiratory muscle strength training programs with and without assistive devices. Therefore, future research should be conducted in which the number of subjects is larger and respiratory muscle strength training programs with and without assistive devices are compared. In conclusion, this study presented respiratory muscle strength training using a sling as a training method for respiratory training because such training may improve the amount of respiration of individual.

\section{REFERENCES}

1) Pryor JA, Prasad SA: Physiotherapy for respiratory and cardiac problems, 3rd ed. Singapore: Churchill Livingstone, 2002, pp 170-176.

2) van der Palen J, Rea TD, Manolio TA, et al.: Respiratory muscle strength and the risk of incident cardiovascular events. Thorax, 2004, 59: 10631067. [Medline] [CrossRef]

3) Teixeira-Salmela LF, Parreira VF, Britto RR, et al.: Respiratory pressures and thoracoabdominal motion in community-dwelling chronic stroke survivors. Arch Phys Med Rehabil, 2005, 86: 1974-1978. [Medline] [CrossRef]

4) Gosselink R: Controlled breathing and dyspnea in patients with chronic obstructive pulmonary disease (COPD). J Rehabil Res Dev, 2003, 40: 25 33. [Medline] [CrossRef]

5) Beckerman M, Magadle R, Weiner M, et al.: The effects of 1 year of specific inspiratory muscle training in patients with COPD. Chest, 2005, 128: 3177-3182. [Medline] [CrossRef]

6) Inzelberg R, Peleg N, Nisipeanu P, et al.: Inspiratory muscle training and the perception of dyspnea in Parkinson's disease. Can J Neurol Sci, 2005, 32: 213-217. [Medline] [CrossRef]

7) Kim J, Park JH, Yim J: Effects of respiratory muscle and endurance training using an individualized training device on the pulmonary function and exercise capacity in stroke patients. Med Sci Monit, 2014, 20: 2543-2549. [Medline] [CrossRef]

8) Sutbeyaz ST, Koseoglu F, Inan L, et al.: Respiratory muscle training im- 
proves cardiopulmonary function and exercise tolerance in subjects with subacute stroke: a randomized controlled trial. Clin Rehabil, 2010, 24: 240-250. [Medline] [CrossRef]

9) Kim JS, Lee YS: Effects of a balloon-blowing exercise on lung function of young adult smokers. J Phys Ther Sci, 2012, 24: 531-534. [CrossRef]

10) Carr M, Jones J: Physiological effects of exercise on stroke survivors. Top Stroke Rehabil, 2003, 9: 57-64. [Medline] [CrossRef]

11) Riolo L, Fisher K: Is there evidence that strength training could help improve muscle function and other outcomes without reinforcing abnormal movement patterns or increasing reflex activity in a man who has had a stroke? Phys Ther, 2003, 83: 844-851. [Medline]

12) Walker J, Cooney M, Norton S: Improved pulmonary function in chronic quadriplegics after pulmonary therapy and arm ergometry. Paraplegia 1989, 27: 278-283. [Medline] [CrossRef]

13) HajGhanbari B, Yamabayashi C, Buna TR, et al.: Effects of respiratory muscle training on performance in athletes: a systematic review with meta-analyses. J Strength Cond Res, 2013, 27: 1643-1663. [Medline] [CrossRef]

14) McCool FD, Tzelepis GE: Inspiratory muscle training in the patient with neuromuscular disease. Phys Ther, 1995, 75: 1006-1014. [Medline]

15) Thomas VS, Hageman PA: Can neuromuscular strength and function in people with dementia be rehabilitated using resistance-exercise training? Results from a preliminary intervention study. J Gerontol A Biol Sci Med Sci, 2003, 58: 746-751. [Medline] [CrossRef]

16) Fiser WM, Hays NP, Rogers SC, et al.: Energetics of walking in elderly people: factors related to gait speed. J Gerontol A Biol Sci Med Sci, 2010, 65: 1332-1337. [Medline] [CrossRef]

17) Bossers WJ, Scherder EJ, Boersma F, et al.: Feasibility of a combined aerobic and strength training program and its effects on cognitive and physical function in institutionalized dementia patients. A pilot study. PLoS ONE, 2014, 9: e97577. [Medline] [CrossRef]

18) Nowak D, Kalucka S, Białasiewicz P, et al.: Exhalation of $\mathrm{H}_{2} \mathrm{O}_{2}$ and thiobarbituric acid reactive substances (TBARs) by healthy subjects. Free Radic Biol Med, 2001, 30: 178-186. [Medline] [CrossRef]

19) Taito S, Domen S, Sekikawa K, et al.: Cigarette smoking does not induce plasma or pulmonary oxidative stress after moderate-intensity exercise. J Phys Ther Sci, 2014, 26: 413-415. [Medline] [CrossRef] 